This item was submitted to Loughborough's Research Repository by the author.

Items in Figshare are protected by copyright, with all rights reserved, unless otherwise indicated.

\title{
Direct integration of cold sintered, temperature-stable Bi2Mo2O9-K2MoO4 ceramics on printed circuit boards for satellite navigation antennas
}

PLEASE CITE THE PUBLISHED VERSION

https://doi.org/10.1016/j.jeurceramsoc.2020.04.025

\section{PUBLISHER}

Elsevier BV

VERSION

AM (Accepted Manuscript)

\section{PUBLISHER STATEMENT}

This paper was accepted for publication in the journal Journal of the European Ceramic Society and the definitive published version is available at https://doi.org/10.1016/j.jeurceramsoc.2020.04.025.

\section{LICENCE}

CC BY-NC-ND 4.0

\section{REPOSITORY RECORD}

Wang, Dawei, Beatia Siame, Shiyu Zhang, Ge Wang, Xingshen Ju, Jinglei Li, Zhilun Lu, et al.. 2020. "Direct Integration of Cold Sintered, Temperature-stable Bi2mo209-k2moo4 Ceramics on Printed Circuit Boards for Satellite Navigation Antennas". Loughborough University. https://hdl.handle.net/2134/12198258.v1. 


\title{
Direct Integration of Cold Sintered, Temperature-Stable $\mathrm{Bi}_{2} \mathrm{Mo}_{2} \mathrm{O}_{9}-$ $\mathrm{K}_{2} \mathrm{MoO}_{4}$ Ceramics on Printed Circuit Boards for Satellite Navigation
}

\author{
Antennas

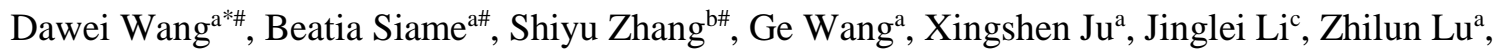 \\ Yiannis Vardaxoglou ${ }^{\mathrm{b}}$, Will Whittow ${ }^{\mathrm{b}}$, Darren Cadman ${ }^{\mathrm{b}}$, Shikuan Sun ${ }^{\mathrm{a}}$, Di Zhou ${ }^{\mathrm{c}}$, Kaixin Song ${ }^{\mathrm{a}, \mathrm{d}}$, \\ Ian M. Reaney ${ }^{\mathrm{a}^{*}}$ \\ ${ }^{a}$ Department of Materials Science and Engineering, University of Sheffield, Sheffield S1 3JD, UK \\ ${ }^{b}$ Wolfson School of Mechanical, Electrical and Manufacturing Engineering, Loughborough University, \\ Loughborough LE11 3TU, UK \\ ${ }^{c}$ Electronic Materials Research Laboratory, Key Laboratory of the Ministry of Education \& International \\ Center for Dielectric Research, Xi'an Jiaotong University, Xi'an 710049, Shaanxi, China \\ ${ }^{d}$ College of Electronics Information, Hangzhou Dianzi University, Hangzhou 310018, China \\ * Corresponding author. E-mail address: dawei.wang@sheffield.ac.uk, i.m.reaney@sheffield.ac.uk \\ \# Author Contributions: D. Wang, B. Siame and S. Zhang contributed equally to this work.
}

\begin{abstract}
$\mathrm{Bi}_{2} \mathrm{Mo}_{2} \mathrm{O}_{9}-\mathrm{K}_{2} \mathrm{MoO}_{4}(\mathrm{BMO}-\mathrm{KMO})$ composite ceramics with $>95 \%$ theoretical density were densified by cold sintering at $150{ }^{\circ} \mathrm{C}$. XRD, Raman, back-scattered SEM and EDX spectroscopy indicated that the BMO and KMO phases coexisted in all composites without inter-diffusion and secondary phases. Temperature coefficient of resonant frequency with near-zero value $\sim-1$ $\mathrm{ppm} /{ }^{\circ} \mathrm{C}$ was acheived for BMO-10\%KMO with pemittivity $\sim 31$ and quality factor $\sim 3,000 \mathrm{GHz}$. Cold-sintered composite ceramics were directly pressed/integrated onto a printed circuit board (PCB) using the $\mathrm{Cu}$ metallisation as a ground plane for the design and fabrication of a circularly polarized microstrip patch antenna suitable for satellite navigation systems which achieved efficiencies $87 \%$ at $1561 \mathrm{MHz}$ (BeiDou) and $88 \%$ at $1575 \mathrm{MHz}$ (GPS/Galileo). The low cost, low energy integration of temperature stable, cold sintered ceramics directly onto a PCB represents a step change in substrate fabrication technology for RF devices.
\end{abstract}

Keywords: microwave dielectric ceramics; cold sintering process; microstrip patch antennas 


\section{Introduction}

Microwave (MW) ceramics are widely used in modern wireless communication systems as resonators, couplers, filters, substrates and capacitors.[1] However, conventional ceramic sintering technology at $>1000{ }^{\circ} \mathrm{C}$ is commonly used to densify ceramics. [2-5] Low-temperature co-fired ceramics (LTCC, $700-900{ }^{\circ} \mathrm{C}$ sintering temperature) and ultra-low temperature co-fired ceramics (ULTCC, $400-600{ }^{\circ} \mathrm{C}$ sintering temperature) can be co-sintered with low cost electrodes ( $\mathrm{Ag}, \mathrm{Cu}$ and $\mathrm{Al}$, etc.). [6-15] To date, temperature-stable MW ceramics cannot be directly integrated onto polymer-based printed circuit boards (PCBs) in a single deposition step from powder. To revolutionize radio frequency (RF) manufacturing therefore, low loss (high quality factor, $Q f \geq 3000 \mathrm{GHz}$ ), temperature-stable (low temperature coefficient of resonant frequency, $\left.\mathrm{TCF}=+/-3 \mathrm{ppm} /{ }^{\circ} \mathrm{C}\right)$, medium permittivity $\left(8<\varepsilon_{\mathrm{r}}<40\right)$ are required that densify at $<200{ }^{\circ} \mathrm{C}$ and permit printing/pressing directly onto PCBs, reducing the costs and energy used in manufacturing and increasing functionality.

The cold sintering process (CSP) can densify materials and devices at $<200{ }^{\circ} \mathrm{C}$ and exhibits great potential for developing novel RF technology and manufacturing processes. Numerous articles have recently appeared on a wide range of materials such as $\mathrm{Li}_{2} \mathrm{MoO}_{4}(\mathrm{LMO}), \mathrm{MoO}_{3}, \mathrm{Na}_{2} \mathrm{Mo}_{2} \mathrm{O}_{7}$ (NMO), $\mathrm{K}_{2} \mathrm{Mo}_{2} \mathrm{O}_{7},(\mathrm{LiBi})_{0.5} \mathrm{MoO}_{4}, \mathrm{LMO}-\mathrm{PTFE}, \mathrm{Al}_{2} \mathrm{SiO}_{5}-\mathrm{NaCl}, \mathrm{LMO}-\mathrm{Mg}_{2} \mathrm{SiO}_{4}$ and LMO$\mathrm{BaFe}_{12} \mathrm{O}_{19}$.[16-31], including a range of temperature stable low loss composites by the present authors, $\mathrm{Na}_{0.5} \mathrm{Bi}_{0.5} \mathrm{MoO}_{4}-\mathrm{LMO},\left(\mathrm{Bi}_{0.95} \mathrm{Li}_{0.05}\right)\left(\mathrm{V}_{0.9} \mathrm{Mo}_{0.1}\right) \mathrm{O}_{4}-\mathrm{NMO}$ and $\mathrm{CaTiO}_{3}-\mathrm{KMO}$ with $8<\varepsilon_{\mathrm{r}}<$ 40.[32-34] Furthermore, standalone RF devices such as temperature stable C0G multilayer ceramic capacitors (MLCCs) and microstrip patch antennas have been fabricated.[34, 35] However, the 'holy grail' of cold-sintered MW ceramics directly pressed/integrated onto PCBs followed by device design and fabrication, has not to date been demonstrated. In this work, $\mathrm{Bi}_{2} \mathrm{Mo}_{2} \mathrm{O}_{9}\left(\mathrm{BMO}, \varepsilon_{\mathrm{r}}=38, \mathrm{TCF}=+31 \mathrm{ppm} /{ }^{\circ} \mathrm{C}, Q \times f=12,500\right)[15,36-38]$ and $\mathrm{KMO}\left(\varepsilon_{\mathrm{r}}=6.4\right.$, $\left.\mathrm{TCF}=-70 \mathrm{ppm} /{ }^{\circ} \mathrm{C}, Q \times f=26,500\right)[33,34]$ were selected with the intent of fabricating MW 
composite ceramics with near-zero TCF. Direct integration of these ceramics onto PCBs is demonstrated followed by the simulation and fabrication of a microstrip patch antenna suitable for satellite navigation systems.

\section{Experimental}

(1-x)BMO-xKMO (x = 5wt $\%, 10 \mathrm{wt} \%, 20 \mathrm{wt} \%, 50 \mathrm{wt} \%, 100 \mathrm{wt} \%)$ composite ceramics were prepared by CSP. BMO powder was synthesised by the solid-state reaction method. Raw chemicals $\mathrm{Bi}_{2} \mathrm{O}_{3}\left(99.9 \%\right.$, Acros Organics) and $\mathrm{MoO}_{3}$ (>99\%, Acros Organics) were weighed with a $\mathrm{Bi}_{2} \mathrm{O}_{3}: \mathrm{MoO}_{3}$ ratio of 1:2 and ball-milled $4 \mathrm{~h}$ in solvent isopropanol. The mixed powders were dried, calcined $4 \mathrm{~h}$ at $630-650^{\circ} \mathrm{C}$ to synthesize the compound and ball-milled $4 \mathrm{~h}$ in isopropanol to reduce particle size. $[15,36-38]$ KMO (Alfa Aesar, > 95\%) and BMO powders were mixed with 5-10 wt \% deionized water, hot-pressed $30 \mathrm{~min}$ at $150{ }^{\circ} \mathrm{C}$ and $600 \mathrm{MPa}$ (Atlas Heated Platens, Specac) and dried $24 \mathrm{~h}$ at $120^{\circ} \mathrm{C}$ to remove residual moisture. BMO ceramics were conventionally sintered at $680{ }^{\circ} \mathrm{C}$ for $2 \mathrm{~h}$.

The densities of ceramic samples were measured by a geometric method.[17-34] Crystal structure, phase assemblage and microstructure were determined by Bruker D2 Phaser X-ray powder diffraction (XRD, $\mathrm{Cu} K \alpha$ radiation), Renishaw inVia Raman microscope Raman spectroscopy and an FEI Inspect F-50 scanning electron microscopy (SEM). The TE $01 \delta$ mode was employed to measure the microwave dielectric properties of ceramics using an Advantest $\mathrm{R} 3767 \mathrm{CH}$ vector network analyzer. The cavity was heated by a Peltier device and the resonant frequency $(f)$ was measured from $25^{\circ} \mathrm{C}$ to $85^{\circ} \mathrm{C}$. The corresponding TCF values were obtained using the formula:

$\mathrm{TCF}=\frac{f_{T}-f_{T_{0}}}{f_{T_{0}} \times\left(T-T_{0}\right)} \times 10^{6}$

where the $f_{T}$ and $f_{T_{0}}$ are the $\mathrm{TE}_{01 \delta}$ resonant frequencies at temperatures, $\mathrm{T}$ and $\mathrm{T}_{0}$, respectively. 


\section{Results and discussion}

The relative density $\left(\rho_{\mathrm{r}}\right)$ of cold-sintered BMO-xKMO composites increases from $90 \%$ for BMO$5 \% \mathrm{KMO}$ to $100 \%$ for $\mathrm{x}>0.05$, Table $\mathrm{I}$, confirming that dense BMO-xKMO composites are readily fabricated by cold sintering.

Table I. Sintering temperature (ST), relative density $\left(\rho_{\mathrm{r}}\right)$, and microwave dielectric properties of BMO-KMO ceramics.

\begin{tabular}{ccccccc}
\hline Composition & $\begin{array}{c}\mathrm{ST} \\
\left({ }^{\circ} \mathrm{C}\right)\end{array}$ & $\rho_{r}(\%)$ & $\varepsilon_{r}$ & $\tan \delta$ & $Q \times f(\mathrm{GHz})$ & $\mathrm{TCF}\left(\mathrm{ppm} /{ }^{\circ} \mathrm{C}\right)$ \\
\hline BMO & 680 & $95 \pm 1.8$ & 38 & 0.0004 & 11000 & +31 \\
BMO-5\%KMO & 150 & $87.3 \pm 2.3$ & 28 & 0.001 & 4700 & +17 \\
BMO-10\%KMO & 150 & $99.6 \pm 1.9$ & 31 & 0.002 & 3000 & -1 \\
BMO-20\%KMO & 150 & $100 \pm 0.6$ & 27 & 0.004 & 1600 & -31 \\
BMO-50\%KMO & 150 & $100 \pm 1.1$ & 22 & 0.006 & 1300 & -55 \\
KMO & 150 & $100 \pm 1.5$ & 6.4 & 0.0003 & 26500 & -70 \\
\hline
\end{tabular}

The XRD patterns of cold-sintered BMO-xKMO ceramics are given in Fig. 1(a). Both BMO and KMO are monoclinic with $P 121 / n 1$ (ICSD: 201742) and C12/m1 (ICSD: 16154) symmetry, respectively.[15, 33, 34, 36-38] $\mathrm{B}$-site $\mathrm{Mo}^{6+}$ cations are coordinated by four O-anions, leading to tightly bound $\mathrm{MoO}_{4}$ tetrahedra. The $\mathrm{A}$-site $\mathrm{Bi}^{3+}$ or $\mathrm{K}^{+}$cations are circled by eight or six $\mathrm{O}$ anions, as displayed in the schematic crystal structures of BMO and KMO (Fig. 1c). Diffraction peaks in the XRD patterns of BMO-xKMO composites may all be ascribed to either $\mathrm{BMO}$ and KMO. The diffraction peak intensity of KMO increases with the weight fraction of KMO increasing, as marked in Fig. 1(a) but no impurity peaks, nor shift in peak position are observed. 
(a)

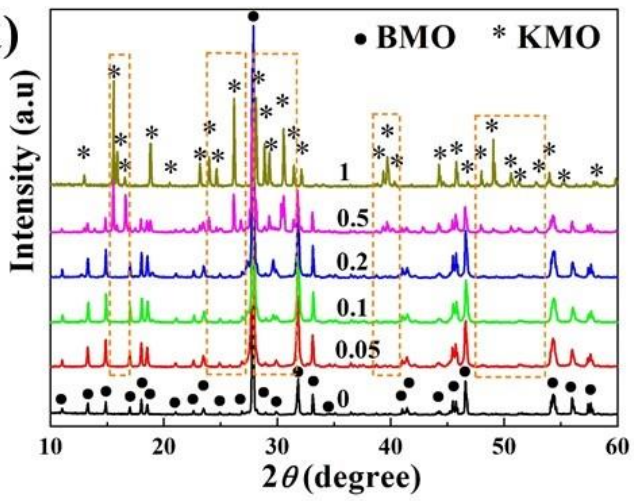

(c)

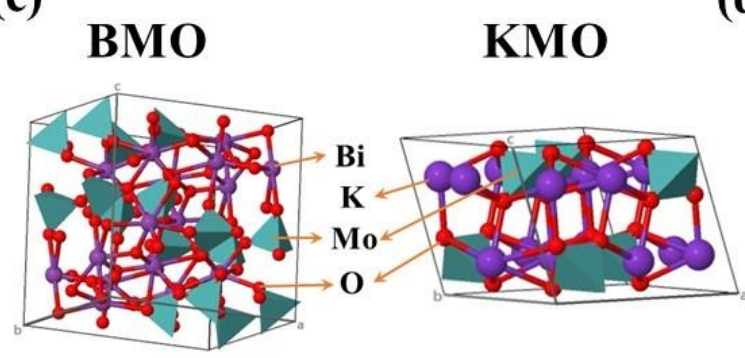

(b)

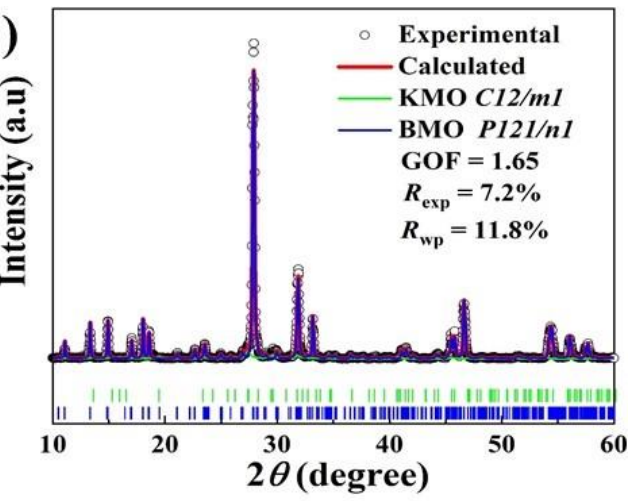

(d)

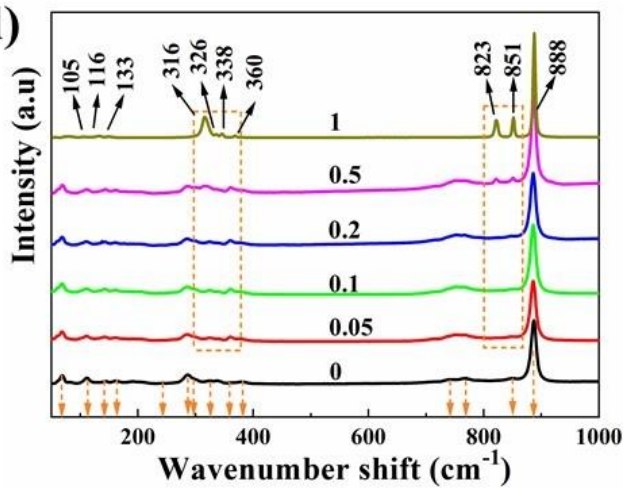

Figure 1. (a) XRD patterns of BMO-xKMO ceramic composites. (b) Rietveld refinement of BMO-10\%KMO. The schematic crystal structures of (c) BMO and KMO. (d) Raman spectra of BMO-xKMO ceramic composites

To further evaluate the phase composition and lattice parameters of BMO-KMO, full-pattern Rietveld refinement of BMO-10\%LMO was performed using a Topas 5 software, where a twophase refinement $(C 12 / \mathrm{ml}+P 121 / \mathrm{nl})$ is used. Low values of $G O F=1.65, R_{\exp }=7.2 \%$ and $R_{\mathrm{wp}}=$ $11.8 \%$ indicate that the calculated result agrees with the observed pattern, Fig. 1(b). The weight fraction of $\mathrm{BMO}(C 12 / \mathrm{ml}, 89 \%)$ and $\mathrm{KMO}(P 121 / \mathrm{nl}, 11 \%)$ phases is determined for BMO$10 \% \mathrm{KMO}$, close to the nominal composition. The calculated lattice parameters are $a=11.9515$ $\AA, b=10.8007 \AA, c=11.8814 \AA$ for $\mathrm{BMO}$ and $a=12.672 \AA, b=6.030 \AA, c=7.066 \AA$ for $\mathrm{KMO}$, respectively, which agree with the reported values. [15, 33, 34, 36-38] 
The room-temperature Raman data of BMO-xKMO composites is shown in Fig. 1(d). In agreement with previous reports, [39, 40] 14 Raman bands are observed in the spectrum of BMO at $68,114,142,176,260,284,296,321,358,380,739,768,851$ and $888 \mathrm{~cm}^{-1}$, which were assigned to bending $\left(260 \sim 380 \mathrm{~cm}^{-1}\right)$ and stretching $\left(739 \sim 888 \mathrm{~cm}^{-1}\right)$ modes of $\mathrm{MoO}_{4}$ tetrahedra and the conversion of $\mathrm{Mo} / \mathrm{Bi}$ atoms $\left(<260 \mathrm{~cm}^{-1}\right)$, respectively. According to group theory, there are 39 different vibrational modes in KMO,[41, 42]:

$\Gamma_{\mathrm{KMO}}=13 \mathrm{~A}_{\mathrm{g}}+7 \mathrm{~A}_{\mathrm{u}}+8 \mathrm{~B}_{\mathrm{g}}+11 \mathrm{~B}_{\mathrm{u}}$

The Raman bands in the range of $100 \sim 160 \mathrm{~cm}^{-1}$ correspond to a combination of the translations and vibrations of $\mathrm{MoO}_{4}$ tetrahedra and translations of $\mathrm{K}$ ions. The $310 \sim 370 \mathrm{~cm}^{-1}$ bands are related to bending modes of $\mathrm{MoO}_{4}$ tetrahedra. The $820 \sim 890 \mathrm{~cm}^{-1}$ bands are related to stretching modes of $\mathrm{MoO}_{4}$ tetrahedra. Raman spectra of BMO-KMO composites therefore, constitute an overlay of Raman bands from individual phases (Fig. 1d). The intensity of Raman modes for KMO increase gradually with increase in $\mathrm{x}$.

SEM images of the cross-section for the cold-sintered BMO-KMO samples are given in Fig. 2(ae). All compositions with $\mathrm{x}>0.05$ have dense microstructures, in agreement with measured densities in Table I. The dark and light regions of contrast in BSE images of mixed BMO-KMO powder (Fig. 2f) and cold-sintered BMO-50\%KMO (Fig. 2g) suggest that two chemically distinct $\mathrm{KMO}$ and BMO rich phases are present which is confirmed by EDS mapping (Fig. 2h-l) and in agreement with Raman spectra and XRD patterns (Fig. 1). 

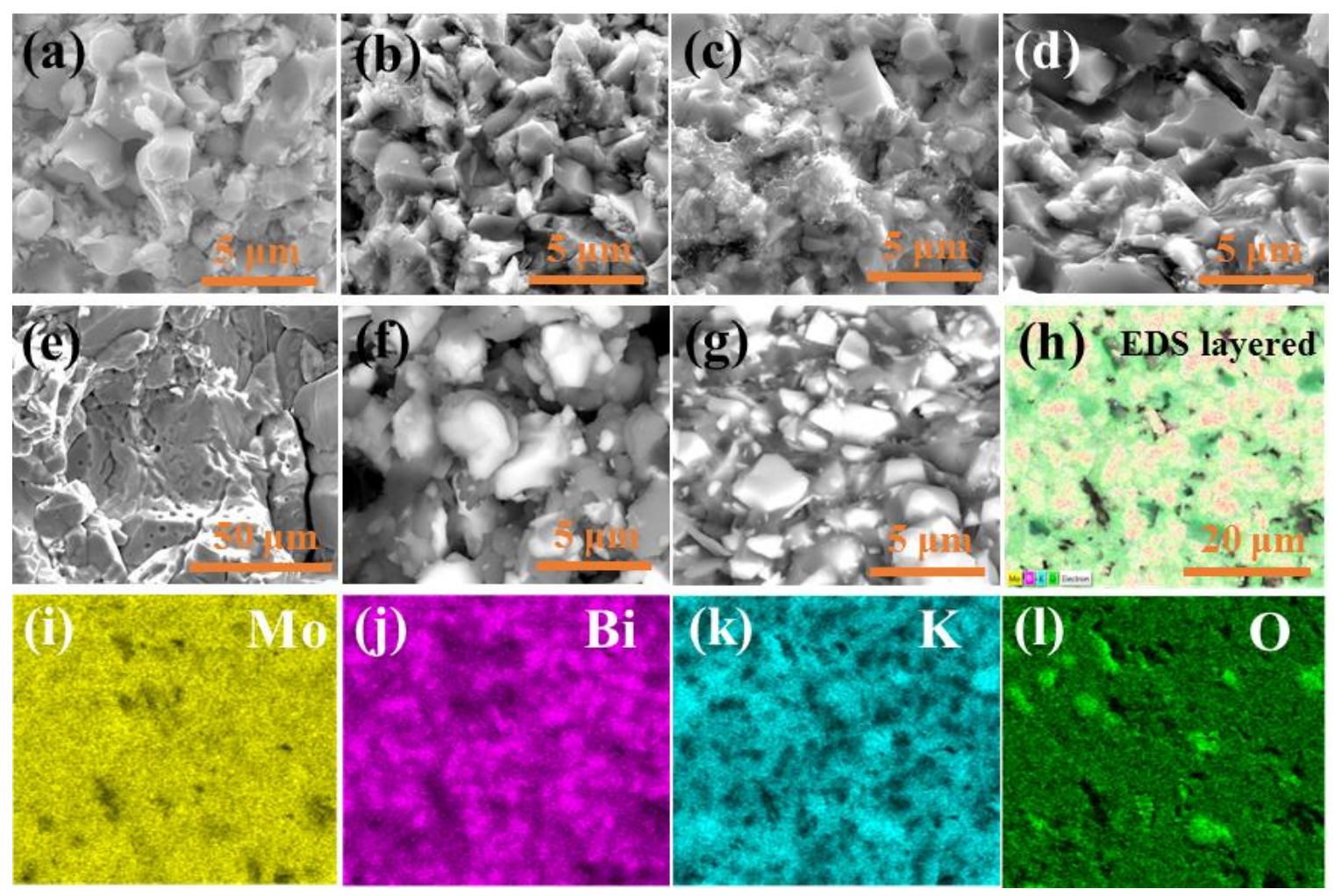

Figure 2. SEM images of the cross-section for cold-sintered BMO-xKMO (a) 5\%, (b) $10 \%$, (c) 20\%, (d) 50\%, (e) 100\%. BSE images of (f) mixed BMO and KMO powder, (g) cold-sintered BMO-50\%KMO cross-section. EDS mapping images of cold-sintered BMO-50\%KMO samples:

(h) elemental layered image, (i) Mo, (j) Bi, (k) K, (l) O.

Fig. 3 shows the microwave dielectric properties of BMO-xKMO ceramic composites with increase of KMO weight fraction, Table I. $\varepsilon_{\mathrm{r}}$ and TCF linearly decrease from 39 and $+31 \mathrm{ppm} /{ }^{\circ} \mathrm{C}$, to 6.4 and $-70 \mathrm{ppm} /{ }^{\circ} \mathrm{C}$, respectively. $Q f$ of BMO-xKMO composites ceramics is lower than both end members and in the range of 1300 4700, likely due to residual amorphous phase in coldsintered systems.[16-34] Near-zero value of TCF $\left(-1 \mathrm{ppm} /{ }^{\circ} \mathrm{C}\right)$ is obtained for BMO-10\% KMO with $\varepsilon_{\mathrm{r}} \sim 31$ and $Q f \sim 3,000 \mathrm{GHz}$. The effective $\varepsilon_{\mathrm{r}}$ can be calculated by the following mixing laws:[32-34]

parallel law, $\varepsilon=V_{1} \varepsilon_{1}+V_{2} \varepsilon_{2}$

series law, $1 / \varepsilon=V_{1} / \varepsilon_{1}+V_{2} / \varepsilon_{2}$ 
logarithmic law, $\varepsilon=\varepsilon_{1}^{V_{1}} \varepsilon_{2}^{V_{2}}$ i.e. $\lg \varepsilon=V_{1} \lg \varepsilon_{1}+V_{2} \lg \varepsilon_{2}$

where $\varepsilon_{1}$ is the $\varepsilon_{\mathrm{r}}$ of phase $1, \varepsilon_{2}$ is the $\varepsilon_{\mathrm{r}}$ of phase $2, V_{1}$ is the volume fraction of phase 1 and $V_{2}(1-$ $V_{1}=V_{2}$ ) is the volume fraction of phase 2. $\varepsilon_{\mathrm{r}}$ follows indicated a parallel mixing law, Fig. 3(a) and 3(b), which may also be used to predict TCF, according to:

$\mathrm{TCF}=V_{1} \mathrm{TCF}_{1}+V_{2} \mathrm{TCF}_{2}$

where $\mathrm{TCF}_{1}$ and $\mathrm{TCF}_{2}$ are the temperature coefficients of phase 1 and 2, respectively, Fig. 3(b).

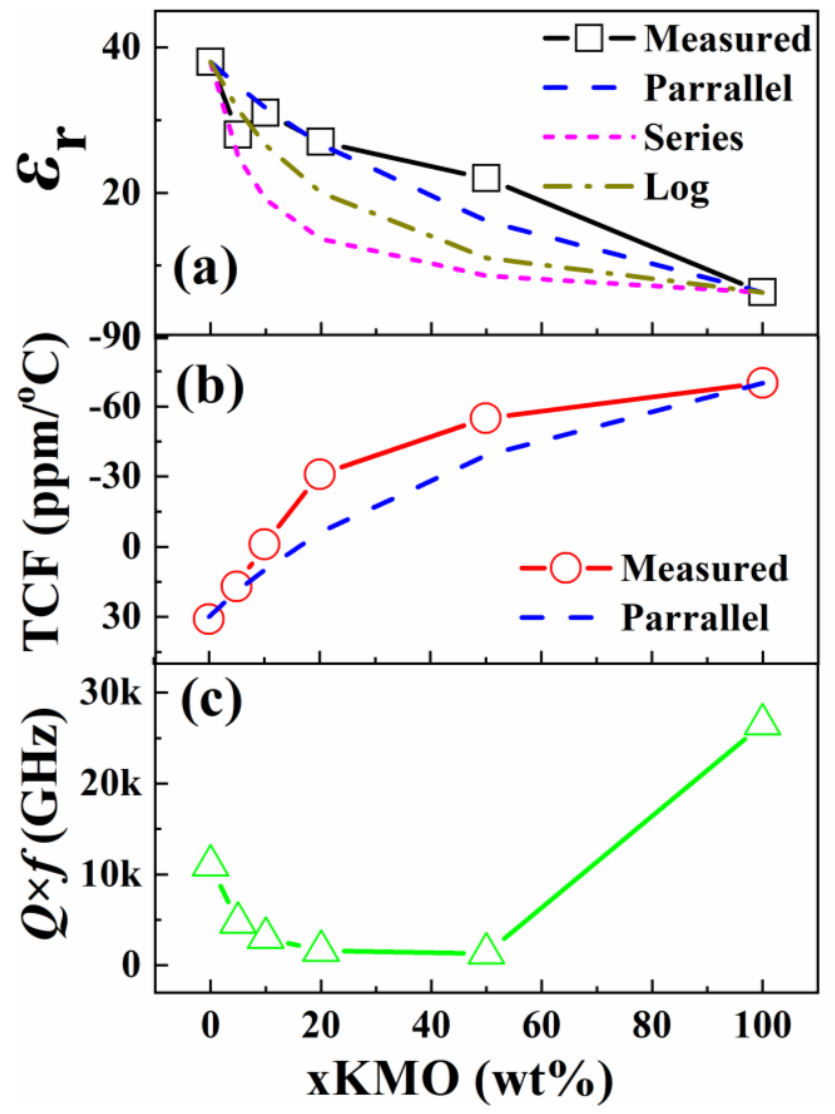

Figure 3. Microwave properties of BMO-xKMO composites vs. KMO weight fraction.

Satellite navigation systems are widely used in consumer electronics and provide navigation, localization, and tracking. The Global Satellite Navigation System (GLONAS), Global Positioning System (GPS), Gallileo and Beidou were installed by Russia, United states, Europe and China, respectively and all operate around 1.5-1.6 GHz. The antenna is one of the key 
components to ensure low latency, good reception to provide high precision positioning and robust communication. Microstrip patch antennas are a popular choice in modern electronics due to their low-profile, low-cost, ease of fabrication and their small physical size for integration into limited space. Generally, ceramic dielectrics with overall dimensions of $20 \mathrm{~mm} \times 20 \mathrm{~mm} \times 2 \mathrm{~mm}$ to $\sim 40 \mathrm{~mm} \times 40 \mathrm{~mm} \times 7 \mathrm{~mm}$ have been widely used as the substrates for satellite navigation antennas for vehicles. Satellite navigation antennas are mainly sold as individual units in which the ceramic is sintered at $>1200{ }^{\circ} \mathrm{C}$ and which require assembling using a 'pick and place' procedure. The modular design helps end-users to reduce cost with respect to customization but some highly integrated, direct compact packaged systems require satellite navigation antennas that can be directly fabricated on PCBs. This is impossible with conventionally sintered ceramics $\left(>1200{ }^{\circ} \mathrm{C}\right)$ but cold sintering densifies powders at less than the melting point $\left(<200{ }^{\circ} \mathrm{C}\right)$ of the PCB board and hence can be directly pressed onto its surface and fully integrated from a manufacturing perspective.

In this work, BMO-10\%KMO ceramic substrates $30 \mathrm{~mm} \times 30 \mathrm{~mm} \times 7 \mathrm{~mm}$ were directly coldsintered onto an $85 \mathrm{~mm} \times 75 \mathrm{~mm} \times 1.6 \mathrm{~mm}$ glass-reinforced epoxy laminate PCB (FR4), as schematically indicated in Fig. 4(a). The Cu layer of the FR4 was intentionally not removed and acted as the ground plane (Fig. 4b). For proof of concept, the top patch was cut from a conductive copper tape with dimensions of $18.5 \mathrm{~mm} \times 18.5 \mathrm{~mm}$ and two cut corners to achieve circular polarization but for mass production, it could be screen printed using a low temperature binderburn out conductive ink. The fabricated antenna is shown in Fig. 4(c). The SEM images and EDS elemental line scans of a cross-section of cold-sintered BMO-10\%KMO on PCBs are shown in Fig. 5. A Cu layer of $\sim 45 \mu \mathrm{m}$ thick is shown in the enlarged BSE image, Fig. 5(a,c), which has a sharp interface with the ceramic grains, indicating chemical/temperature compatibility with the BMO-KMO layer, further confirmed from the EDS elemental line-scans, Fig. 5(c). 


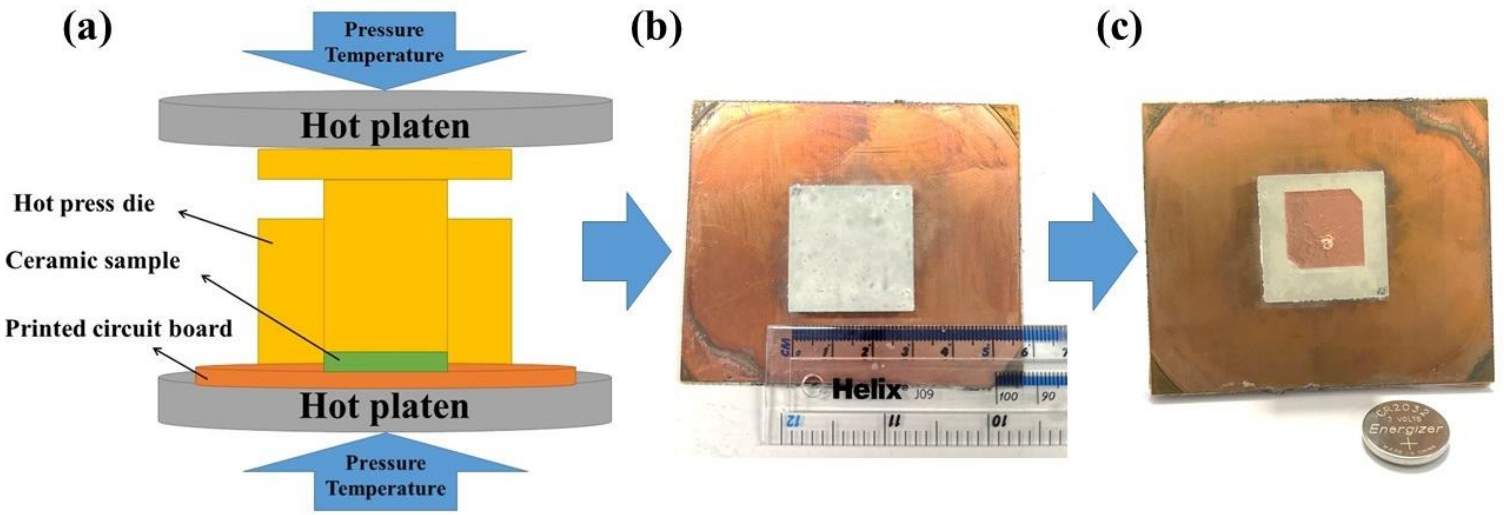

Figure 4. (a) The schematic diagram of cold-sintering ceramic substrate for antenna. (b) coldsintered BMO-10\% KMO ceramic substrate with a dimension of $30 \mathrm{~mm} \times 30 \mathrm{~mm} \times 7 \mathrm{~mm}$ on an $85 \mathrm{~mm} \times 75 \mathrm{~mm} \times 1.6 \mathrm{~mm}$ glass-reinforced epoxy laminate PCB (FR4). (c) The fabricated antenna with cold-sintered BMO-10\% KMO ceramic as substrate.
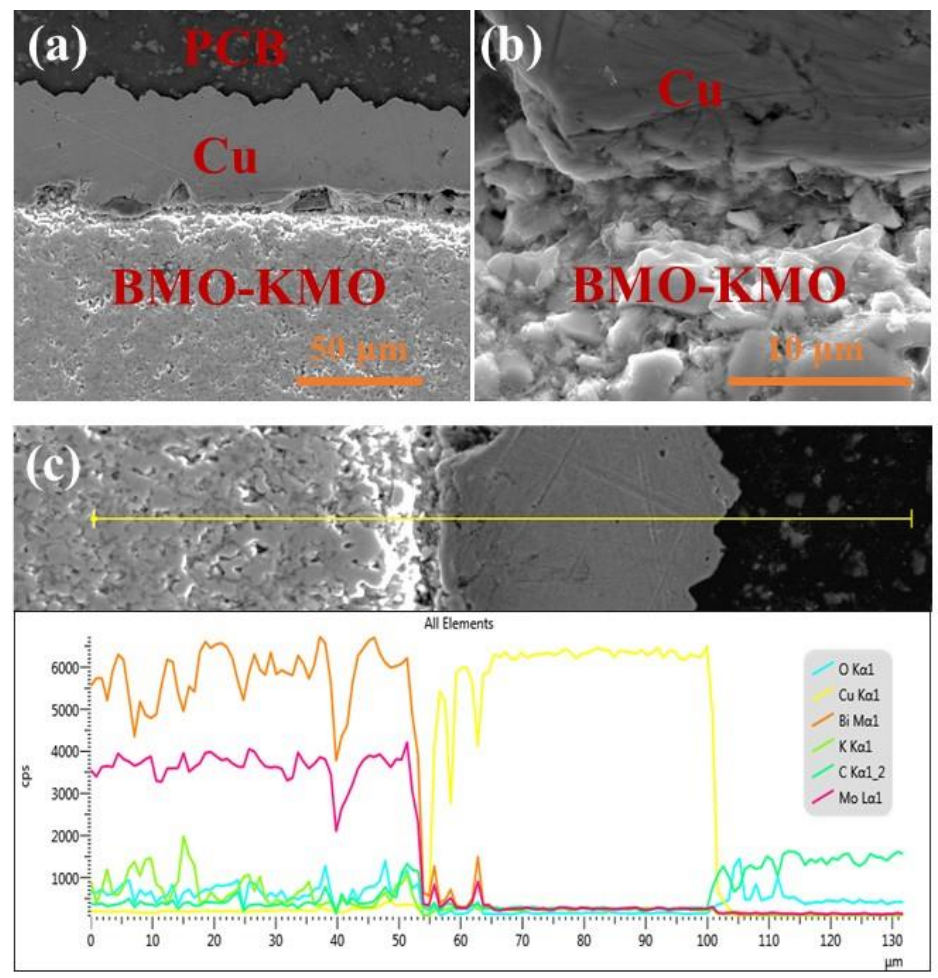

Figure 5. (a, b) SEM images (c) EDS elemental line-scans of a cross-section of cold-sintered $\mathrm{BMO}-10 \% \mathrm{KMO}$ on a $\mathrm{Cu}$ metallised PCB. 
The antenna gave a right-hand circular polarization (RHCP) across a wide operating frequency and supported the B1I (1561 MHz) band for BeiDou, L1 (1575 MHz) GPS and E1 (1575 MHz) for Galileo. The measured S11 is shown in Fig. 6(a), indicating that the ceramic microstrip patch antenna is well matched and has $-10 \mathrm{~dB}$ bandwidth of $59 \mathrm{MHz}$ that covers the desired frequency $1561 \mathrm{MHz}$ and $1575 \mathrm{MHz}$. The far-field performance of the antenna was measured in an anechoic chamber and the parameters are summarized in Table II. The total antenna efficiencies (include the $\mathrm{S} 11$ mismatch) are $87 \%$ at $1561 \mathrm{MHz}$ (BeiDou) and $88 \%$ at $1575 \mathrm{MHz}$ (GPS/Galileo). The axial ratio was $<3 \mathrm{~dB}$ at both frequencies which indicated good circular polarization. The circular polarization performance is particularly important for satellite navigation applications since the relative orientation of the transmitting and receiving antennas is not fixed, and the circularly polarization is able to overcome the Faraday rotation effect due to the ionosphere thereby maximising signal reception. The measured radiation patterns at $1561 \mathrm{MHz}$ and $1575 \mathrm{MHz}$ of the ceramic microstrip antenna are shown in Fig. 6(b-e), respectively.
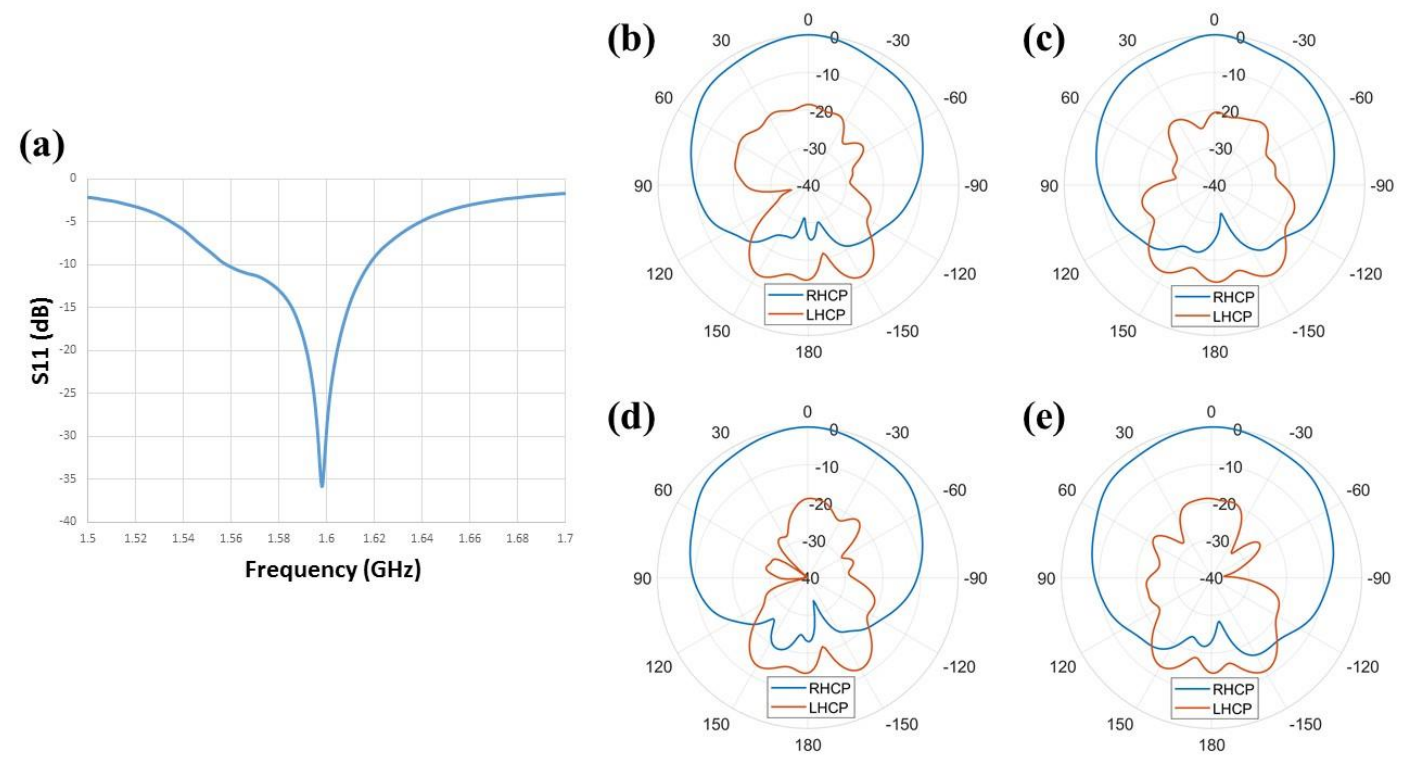
Figure. 6. (a) Measured S11 curve; Measured radiation patterns in Azimuth (b) and Elevation plane (c) at $1561 \mathrm{MHz}$; Measured radiation patterns in Azimuth (d) and Elevation plane (e) at $1575 \mathrm{MHz}$.

Table II. Measured antenna performance of the fabricated ceramic microstrip patch antenna at two frequency bands.

\begin{tabular}{ccc}
\hline Parameters & BeiDou & GPS/Galileo \\
\hline Frequency & $1561 \mathrm{MHz}$ & $1575 \mathrm{MHz}$ \\
Polarization & RHCP & RHCP \\
Gain & $5.7 \mathrm{dBic}$ & $5.8 \mathrm{dBic}$ \\
Directivity & $6.4 \mathrm{dBic}$ & $6.4 \mathrm{dBic}$ \\
Total efficiency & $87 \%$ & $88 \%$ \\
Axial ratio & $2.1 \mathrm{~dB}$ & $1.9 \mathrm{~dB}$ \\
\hline
\end{tabular}

\section{Conclusions}

BMO-KMO microwave ceramic composites with high relative densities $(90 \%-100 \%)$ were successfully fabricated by cold sintering at $150{ }^{\circ} \mathrm{C} / 30 \mathrm{~min} / 600 \mathrm{MPa}$. Only BMO and $\mathrm{KMO}$ were presented in composites and no chemical reaction occurred between the two end-members, as confirmed by XRD, Raman, BSE and EDS mapping. With increasing weight fraction of KMO, $\varepsilon_{\mathrm{r}}$ and TCF decreased while $Q f$ increased. TCF $\sim+1 \mathrm{ppm} /{ }^{\circ} \mathrm{C}$ was achvieved in $\mathrm{BMO}-10 \% \mathrm{KMO}$ with $Q f \sim 3,000 \mathrm{GHz}$ and $\varepsilon_{r} \sim 31$. An antenna for satellite navigation was designed and then fabricated using a BMO-10\%KMO substrate $(30 \times 30 \times 7 \mathrm{~mm})$ directly pressed onto a $\mathrm{PCB}$ metallised circuit board using the $\mathrm{Cu}$ layer as a ground plane. The antenna had an S11 of $-10 \mathrm{~dB}$ with bandwidth of $59 \mathrm{MHz},<3 \mathrm{~dB}$ axial ratio that covers the desired frequency bands $1561 \mathrm{MHz}$ and $1575 \mathrm{MHz}$. The antenna works well at both BeiDou and GPS/Galileo frequencies with efficiencies of $87 \%$ at $1561 \mathrm{MHz}$ and $88 \%$ at $1575 \mathrm{MHz}$. 


\section{Acknowledgments}

We thank the funding and supporting from EPSRC (EP/L017563/1, EP/N010493/1).

\section{References}

[1] I.M. Reaney, D. Iddles, Microwave dielectric ceramics for resonators and filters in mobile phone networks, J Am Ceram Soc 89(7) (2006) 2063-2072.

[2] T. Ibn-Mohammed, C.A. Randall, K. Mustapha, J. Guo, J. Walker, S. Berbano, S. Koh, D. Wang, D. Sinclair, I. Reaney, Decarbonising ceramic manufacturing: A techno-economic analysis of energy efficient sintering technologies in the functional materials sector, $\mathrm{J}$ Eur Ceram Soc 39(16) (2019) 5213-5235.

[3] Z. Song, K. Song, B. Liu, P. Zheng, H. Barzegar Bafrooei, W. Su, H. Lin, F. Shi, D. Wang, I. Reaney, Temperature-dependent dielectric and Raman spectra and microwave dielectric properties of gehlenite-type $\mathrm{Ca}_{2} \mathrm{Al}_{2} \mathrm{SiO}_{7}$ ceramics, International Journal of Applied Ceramic Technology 17(2) (2020) 771-777.

[4] Q. Lin, K. Song, B. Liu, H.B. Bafrooei, D. Zhou, W. Su, F. Shi, D. Wang, H. Lin, I.M. Reaney, Vibrational spectroscopy and microwave dielectric properties of $\mathrm{AY}_{2} \mathrm{Si}_{3} \mathrm{O}_{10}(\mathrm{~A}=\mathrm{Sr}, \mathrm{Ba})$ ceramics for 5G applications, Ceram Int 46(1) (2020) 1171-1177.

[5] D. Zhou, D. Guo, W.B. Li, L.X. Pang, X. Yao, D.W. Wang, I.M. Reaney, Novel temperature stable high- $\varepsilon_{\mathrm{r}}$ microwave dielectrics in the $\mathrm{Bi}_{2} \mathrm{O}_{3}-\mathrm{TiO}_{2}-\mathrm{V}_{2} \mathrm{O}_{5}$ system, J Mater Chem C 4(23) (2016) 5357-5362.

[6] H.H. Guo, D. Zhou, W.F. Liu, L.X. Pang, D.W. Wang, J.Z. Su, Z.M. Qi, Microwave dielectric properties of temperature-stable zircon-type $(\mathrm{Bi}, \mathrm{Ce}) \mathrm{VO}_{4}$ solid solution ceramics, J Am Ceram Soc 103(1) (2020) 423-431.

[7] H.H. Guo, D. Zhou, L.X. Pang, Z.M. Qi, Microwave dielectric properties of low firing temperature stable scheelite structured $(\mathrm{Ca}, \mathrm{Bi})(\mathrm{Mo}, \mathrm{V}) \mathrm{O}_{4}$ solid solution ceramics for LTCC applications, J Eur Ceram Soc 39(7) (2019) 2365-2373. 
[8] D. Zhou, L.X. Pang, D.W. Wang, I.M. Reaney, $\mathrm{BiVO}_{4}$ based high k microwave dielectric materials: a review, J Mater Chem C 6(35) (2018) 9290-9313.

[9] D. Zhou, L.X. Pang, D.W. Wang, Z.M. Qi, I.M. Reaney, High quality factor, ultralow sintering temperature $\mathrm{Li}_{6} \mathrm{~B}_{4} \mathrm{O}_{9}$ microwave dielectric ceramics with ultralow density for antenna substrates, Acs Sustain Chem Eng 6(8) (2018) 11138-11143.

[10] L.X. Pang, D. Zhou, D.W. Wang, J.X. Zhao, W.G. Liu, Z.X. Yue, I.M. Reaney, Temperature stable $\mathrm{K}_{0.5}\left(\mathrm{Nd}_{1-}{ }_{\mathrm{x}} \mathrm{Bi}_{\mathrm{x}}\right)_{0.5} \mathrm{MoO}_{4}$ microwave dielectrics ceramics with ultra-low sintering temperature, J Am Ceram Soc 101(5) (2018) 1806-1810.

[11] D. Zhou, L.X. Pang, D.W. Wang, H.H. Guo, F. Yang, Z.M. Qi, C. Li, B.B. Jin, I.M. Reaney, Crystal structure, impedance and broadband dielectric spectra of ordered scheelite-structured $\mathrm{Bi}\left(\mathrm{Sc}_{1 / 3} \mathrm{Mo}_{2 / 3}\right) \mathrm{O}_{4}$ ceramic, J Eur Ceram Soc 38(4) (2018) 1556-1561.

[12] D. Zhou, L.X. Pang, D.W. Wang, C. Li, B.B. Jin, I.M. Reaney, High permittivity and low loss microwave dielectrics suitable for $5 \mathrm{G}$ resonators and low temperature co-fired ceramic architecture, J Mater Chem C 5(38) (2017) 10094-10098.

[13] D. Zhou, J. Li, L.-X. Pang, D.-W. Wang, I.M. Reaney, Novel water insoluble $\left(\mathrm{Na}_{\mathrm{x}} \mathrm{Ag}_{2-\mathrm{x}}\right)$ $\mathrm{MoO}_{4}(0 \leq \mathrm{x} \leq 2)$ microwave dielectric ceramics with spinel structure sintered at 410 degrees, $\mathrm{J}$ Mater Chem C 5(24) (2017) 6086-6091.

[14] D. Zhou, J. Li, L.-X. Pang, G.-H. Chen, Z.-M. Qi, D.-W. Wang, I.M. Reaney, Crystal structure, infrared spectra, and microwave dielectric properties of temperature-stable zircon-type (Y,Bi) $\mathrm{VO}_{4}$ solid-solution ceramics, Acs Omega 1(5) (2016) 963-970.

[15] R. Gheisari, H. Chamberlain, G. Chi-Tangyie, S. Zhang, A. Goulas, C.-K. Lee, T. Whittaker, D. Wang, A. Ketharam, A. Ghosh, Multi-material additive manufacturing of low sintering temperature $\mathrm{Bi}_{2} \mathrm{Mo}_{2} \mathrm{O}_{9}$ ceramics with Ag floating electrodes by selective laser burnout, Virtual and Physical Prototyping 15(2) (2020) 133-147. 
[16] H. Kahari, M. Teirikangas, J. Juuti, H. Jantunen, Dielectric Properties of Lithium Molybdate Ceramic Fabricated at Room Temperature, J Am Ceram Soc 97(11) (2014) 3378-3379.

[17] H. Kahari, M. Teirikangas, J. Juuti, H. Jantunen, Room-temperature fabrication of microwave dielectric $\mathrm{Li}_{2} \mathrm{MoO}_{4}-\mathrm{TiO}_{2}$ composite ceramics, Ceram Int 42(9) (2016) 11442-11446. [18] M. Vaataja, H. Kahari, J. Juuti, H. Jantunen, $\mathrm{Li}_{2} \mathrm{MoO}_{4}$-based composite ceramics fabricated from temperature- and atmosphere-sensitive MnZn ferrite at room temperature, J Am Ceram Soc 100(8) (2017) 3626-3635.

[19] M. Vaataja, H. Kahari, K. Ohenoja, M. Sobocinski, J. Juuti, H. Jantunen, 3D printed dielectric ceramic without a sintering stage, Sci Rep-Uk 8 (2018).

[20] J. Guo, H.Z. Guo, A.L. Baker, M.T. Lanagan, E.R. Kupp, G.L. Messing, C.A. Randall, Cold Sintering: A Paradigm Shift for Processing and Integration of Ceramics, Angew Chem Int Edit 55(38) (2016) 11457-11461.

[21] J. Guo, S.S. Berbano, H.Z. Guo, A.L. Baker, M.T. Lanagan, C.A. Randall, Cold Sintering Process of Composites: Bridging the Processing Temperature Gap of Ceramic and Polymer Materials, Adv Funct Mater 26(39) (2016) 7115-7121.

[22] A. Baker, H.Z. Guo, J. Guo, C. Randall, Utilizing the Cold Sintering Process for FlexiblePrintable Electroceramic Device Fabrication, J Am Ceram Soc 99(10) (2016) 3202-3204.

[23] J. Guo, A.L. Baker, H.Z. Guo, M. Lanagan, C.A. Randall, Cold sintering process: A new era for ceramic packaging and microwave device development, J Am Ceram Soc 100(2) (2017) 669677.

[24] J.P. Maria, X.Y. Kang, R.D. Floyd, E.C. Dickey, H.Z. Guo, J. Guo, A. Baker, S. Funihashi, C.A. Randall, Cold sintering: Current status and prospects, J Mater Res 32(17) (2017) 3205-3218. [25] J. Guo, X.T. Zhao, T.H. De Beauvoir, J.H. Seo, S.S. Berbano, A.L. Baker, C. Azina, C.A. Randall, Recent Progress in Applications of the Cold Sintering Process for Ceramic-Polymer Composites, Adv Funct Mater 28(39) (2018). 
[26] I.J. Induja, M.T. Sebastian, Microwave dielectric properties of mineral sillimanite obtained by conventional and cold sintering process, J Eur Ceram Soc 37(5) (2017) 2143-2147.

[27] W.B. Hong, L. Li, M. Cao, X.M. Chen, Plastic deformation and effects of water in roomtemperature cold sintering of $\mathrm{NaCl}$ microwave dielectric ceramics, J Am Ceram Soc 101(9) (2018) 4038-4043.

[28] Y. Liu, P. Liu, C.X. Hu, Low-temperature preparation and microwave dielectric properties of cold sintered $\mathrm{Li}_{2} \mathrm{Mg}_{3} \mathrm{TiO}_{6}$ nanocrystalline ceramics, Ceram Int 44(17) (2018) 21047-21052.

[29] S.S. Faouri, A. Mostaed, J.S. Dean, D.W. Wang, D.C. Sinclair, S.Y. Zhang, W.G. Whittow, Y. Vardaxoglou, I.M. Reaney, High quality factor cold sintered $\mathrm{Li}_{2} \mathrm{MoO}_{4}-\mathrm{BaFe}_{12} \mathrm{O}_{19}$ composites for microwave applications, Acta Mater 166 (2019) 202-207.

[30] D. Zhou, L.X. Pang, D.W. Wang, I.M. Reaney, Novel water-assisting low firing $\mathrm{MoO}_{3}$ microwave dielectric ceramics, J Eur Ceram Soc 39(7) (2019) 2374-2378.

[31] Y. Ji, K. Song, X. Luo, B. Liu, H. Barzegar Bafrooei, D. Wang, Microwave dielectric properties of (1-x) $\mathrm{Li}_{2} \mathrm{MoO}_{4}-\mathrm{xMg}_{2} \mathrm{SiO}_{4}$ composite ceramics fabricated by cold sintering process, Frontiers in Materials 6 (2019) 256.

[32] D.W. Wang, D. Zhou, S.Y. Zhang, Y. Vardaxoglou, W.G. Whittow, D. Cadman, I.M. Reaney, Cold-Sintered Temperature Stable $\mathrm{Na}_{0.5} \mathrm{Bi}_{0.5} \mathrm{MoO}_{4}-\mathrm{Li}_{2} \mathrm{MoO}_{4}$ Microwave Composite Ceramics, Acs Sustain Chem Eng 6(2) (2018) 2438-2444.

[33] D.W. Wang, S.Y. Zhang, D. Zhou, K.X. Song, A. Feteira, Y. Vardaxoglou, W. Whittow, D. Cadman, I.M. Reaney, Temperature Stable Cold Sintered $\left(\mathrm{Bi}_{0.95} \mathrm{Li}_{0.05}\right)\left(\mathrm{V}_{0.9} \mathrm{Mo}_{0.1}\right) \mathrm{O}_{4}-\mathrm{Na}_{2} \mathrm{Mo}_{2} \mathrm{O}_{7}$ Microwave Dielectric Composites, Materials 12(9) (2019).

[34] D. Wang, S. Zhang, G. Wang, Y. Vardaxoglou, W. Whittow, D. Cadman, D. Zhou, K. Song, I.M. Reaney, Cold sintered $\mathrm{CaTiO}_{3}-\mathrm{K}_{2} \mathrm{MoO}_{4}$ microwave dielectric ceramics for integrated microstrip patch antennas, Applied Materials Today 18 (2020) 100519.

[35] D.W. Wang, D. Zhou, K.X. Song, A. Feteira, C.A. Randall, I.M. Reaney, Cold-Sintered C0G Multilayer Ceramic Capacitors, Adv Electron Mater 5(7) (2019). 
[36] D. Zhou, H. Wang, L.X. Pang, C.A. Randall, X. Yao, $\mathrm{Bi}_{2} \mathrm{O}_{3}-\mathrm{MoO}_{3}$ Binary System: An Alternative Ultralow Sintering Temperature Microwave Dielectric, J Am Ceram Soc 92(10) (2009) 2242-2246.

[37] D. Zhou, H. Wang, X. Yao, L.X. Pang, Microwave Dielectric Properties of Low Temperature Firing $\mathrm{Bi}_{2} \mathrm{Mo}_{2} \mathrm{O}_{9}$ Ceramic, J Am Ceram Soc 91(10) (2008) 3419-3422.

[38] D. Zhou, C.A. Randall, A. Baker, H. Wang, L.X. Pang, X. Yao, Dielectric Properties of an Ultra-Low-Temperature Cofiring $\mathrm{Bi}_{2} \mathrm{Mo}_{2} \mathrm{O}_{9}$ Multilayer, J Am Ceram Soc 93(5) (2010) 14431446.

[39] F.D. Hardcastle, I.E. Wachs, Molecular-Structure of Molybdenum Oxide in Bismuth Molybdates by Raman-Spectroscopy, J Phys Chem-Us 95(26) (1991) 10763-10772.

[40] K. Seevakan, A. Manikandan, P. Devendran, Y. Slimani, A. Baykal, T. Alagesan, Structural, magnetic and electrochemical characterizations of $\mathrm{Bi}_{2} \mathrm{Mo}_{2} \mathrm{O}_{9}$ nanoparticle for supercapacitor application, J Magn Magn Mater 486 (2019).

[41] W. Paraguassu, G.D. Saraiva, S. Guerini, P.T.C. Freire, B.T.O. Abagaro, J. Mendes, Pressure-induced phase transition on $\mathrm{K}_{2} \mathrm{MoO}_{4}$ : A Raman scattering study and ab initio calculations, J Solid State Chem 196 (2012) 197-202.

[42] G.D. Saraiva, W. Paraguassu, P.T.C. Freire, M. Maczka, J. Mendes, Temperature-dependent Raman scattering study of $\mathrm{K}_{2} \mathrm{MoO}_{4}$, Vib Spectrosc 58 (2012) 87-94. 